\title{
Corrigendum: Hypothalamic miRNAs: emerging roles in energy balance control
}

\author{
Marc Schneeberger ${ }^{1,2,3}$, Alicia G. Gómez-Valadés ${ }^{1,3}$, Sara Ramírez ${ }^{1}$, Ramon Gomis ${ }^{1,2,3}$ \\ and Marc Claret ${ }^{1 *}$ \\ ${ }^{1}$ Diabetes and Obesity Research Laboratory, Institut d'Investigacions Biomèdiques August Pi i Sunyer, Barcelona, Spain, \\ ${ }^{2}$ Endocrinology and Nutrition, Hospital Clínic - University of Barcelona, Barcelona, Spain, ${ }^{3}$ CIBER de Diabetes y \\ Enfermedades Metabólicas Asociadas, Barcelona, Spain
}

Keywords: miRNA, Hypothalamus, obesity, diabetes mellitus, POMC neurons

\section{A corrigendum on}

\section{OPEN ACCESS}

Edited and reviewed by: Miguel Lopez,

University of Santiago de Compostela

Spain

${ }^{*}$ Correspondence: Marc Claret, mclaret@clinic.ub.es

Specialty section:

This article was submitted to Neuroendocrine Science, a section of the journal Frontiers in Neuroscience

Received: 20 February 2015 Accepted: 06 March 2015

Published: 20 March 2015

Citation:

Schneeberger M, Gómez-Valadés AG, Ramirez S, Gomis $R$ and Claret $M$ (2015) Corrigendum: Hypothalamic miRNAs: emerging roles in energy balance control. Front. Neurosci. 9:96. doi: 10.3389/fnins.2015.00096
Hypothalamic miRNAs: emerging roles in energy balance control

by Schneeberger, M., Gomez-Valadés, A. G., Ramirez, S., Gomis, R., and Claret, M. (2015). Front. Neurosci. 9:41. doi: 10.3389/fnins.2015.00041

The acknowledgments section for this mini-review article was accidentally omitted.

\section{Acknowledgments}

This work was supported by Grants PI13/01604, PI10/01074 from National R+D+I (Ministerio de Ciencia e Innovación; MICINN) cofunded by Instituto Salud Carlos III (ISCIII) and the ERDF (MC). Marie Curie People Cofund Fellowship, Seventh Framework Programme of the European Commission grant 267248:DIATRAIN (AGG-V). MS is a recipient of an undergraduate grant from the University of Barcelona. MC is a recipient of a Miguel Servet contract (MICINN-ISCIII, CP09/00233). This work was carried out in part at the Esther Koplowitz Centre.

Conflict of Interest Statement: The authors declare that the research was conducted in the absence of any commercial or financial relationships that could be construed as a potential conflict of interest.

Copyright () 2015 Schneeberger, Gómez-Valadés, Ramírez, Gomis and Claret. This is an open-access article distributed under the terms of the Creative Commons Attribution License (CC BY). The use, distribution or reproduction in other forums is permitted, provided the original author(s) or licensor are credited and that the original publication in this journal is cited, in accordance with accepted academic practice. No use, distribution or reproduction is permitted which does not comply with these terms. 